\title{
Los resúmenes científicos a congresos y sus publicaciones in-extenso: Una dirección cada vez mas infrecuente.
}

\author{
Guillermo Lema
}

Profesor Titular. División de Anestesiología. Facultad de Medicina. Pontificia Universidad Católica de Chile. Santiago, Chile.

Es llamativo y sorprendente el número de resúmenes científicos que presentan algunos colegas en los congresos científicos.

¿Qué hay en el fondo?

Dependiendo de las especialidades, en todas aquellas con congresos anuales, no más del $20 \%$ termina en una publicación formal y no más del $10 \%$ en revistas indexadas.

Los resúmenes de trabajos presentados en congresos científicos en Chile o en el extranjero, son, o más bien debieran ser el resultado de un trabajo de investigación realizado bajo las directrices que el método científico sugiere. Aquellos investigadores reconocidos y de trayectoria en diversas áreas, cumplen generalmente con estas normas. Estos grupos de trabajo, cuál más, cuál menos, terminan sus trabajos con publicaciones formales in-extenso. Investigadores jóvenes o iniciándose en el difícil campo de la investigación debieran ser "tutoreados" por aquellos de más trayectoria, como una manera de que la o las investigaciones, constituyan líneas de trabajo que aporten. Investiga- ción esporádica o con "destino incierto" debieran ser cuidadosamente observadas para no dilapidar esfuerzos ni recursos siempre tan escasos. No quisiera dar a entender que solo los investigadores formales son los únicos que pueden publicar, pero sin lugar son ellos los más preparados.

El número de resúmenes presentados a los congresos supera con creces lo que uno podría esperar como un esfuerzo serio al desarrollo de una especialidad. Entonces ¿por qué no terminamos el trabajo y publicamos lo que hemos esbozado en un resumen científico?

Tres son a mi juicio razones importantes para que esto ocurra:

- Enormes bases de datos permiten que cualquier profesional de la salud, incluyendo estudiantes, puedan hurgar en ellos y usando herramientas estadísticas variadas, establecer alguna cosa que parezca ciencia. Obtener una " $p$ " de valor significativo no significa que lo estudiado sea necesariamente válido o relevante. Lamentablemente, las bases de datos, los paquetes estadísticos y una deficiente 
formación en investigación contribuye a que ello ocurra. - Con el fin de completar un buen curriculum, los profesionales somos conminados a presentar casos clínicos poco originales, casuísticas nada de novedosas e intentos de investigación sin ningún (o muy poco) fundamento en bases científicas sólidas.

Los ascensos académicos, las calificaciones e incentivos profesionales, las postulaciones a estudios de postgrado, son fuente de confusión. Creemos que cualquier resumen presentado es suficiente para lograr las metas propuestas. Lamentablemente, no hay claridad acerca de que es lo que sirve y que cosa es solo eso, "una presentación en un congreso".

- Finalmente, pero cada vez de mayor trascendencia, los laboratorios comerciales estimulan o derechamente incentivan a los profesionales de la salud para producir trabajos cuyo fin es solo el uso a larga mano de un determinado fármaco o equipo.

Las autoridades involucradas y las sociedades científicas pueden es más, debieran, dar reglamentaciones muy claras para no seguir contribuyendo a confundir más este difícil camino del desarrollo del conocimiento.

\section{Referencias:}

1 HUMBERTO REYES B, MAX ANDRESEN H, JOAQUÍN PALMAH. La importacia y el destino de los resúmenes presentados en reuniones científicas. Rev. Médica de Chile 2011; 139 : 7-10. 
Fé de erratas

Los siguientes errores fueron detectados en el trabajo publicado en la Rev Chil Cardiol 2011; 30: 34-41, "Mayor actividad de Rho kinasa en leucocitos circulantes se asocia a estrés oxidativo y rigidez arterial en hipertensos diabéticos", de los autores Luigi Gabrielli, et al., y se corrigen a continuación.

1.Se omitió el Financiamiento. Debe decir:

Mayor actividad de Rho kinasa en leucocitos circulantes se asocia a estrés oxidativo y rigidez arterial en hipertensos diabéticos.

Luigi Gabrielli, Alejandro Berkovitz, Italo Mora, Ulises Novoa, Iván Godoy, Paul MacNab, Samuel Córdova, Ivonne Padilla, Paola Rigotti, Lorena García, Sergio Lavandero, María Paz Ocaranza, Jorge Jalil,

División de Enfermedades Cardiovasculares. Pontificia Universidad Católica de Chile.

FINANCIAMIENTO FONDECYT 1085208
2. Se cometió un error en el año de publicación, consignándolo como del 2010.

Debe decir:

Rev. Chil Cardiol 2011; 30: 34-41 